\title{
Críticos decimonónicos de la Biblia. Ensayo sobre Engels y Bakunin como lectores
}

PAULA BRUNO

UNIVERSIDAD DE BUENOS AIRES - CONICET

ABSTRACT: The article proposes an approach to two intellectual people of the end of the nineteenth century: Friedrich Engels and Mijail Bakunin. The paper focuses on them as readers of the Bible. It analyses the following titles: God and the State (M. Bakunin, published in 1870 approximately) and the "Study about the history of ancient Christianity" (F. Engels, written in 1890 approximately). Both authors are distinguished exponents of nineteenth century readers of the Bible. As peculiar critics of the Enlightenment, each of them relied on theses that go beyond the anti-rationalist reaction of Romanticism. Bakunin and Engels point out that behind the critical reason of the Enlightment lies a legitimizing reason of the capitalist society. From this premise, they recovered, radicalized, the critique to the Christian prejudices already present in the eighteenth century philosophers. As strong antiChristian thinkers, they attacked the traditional Christian doctrine in most of their works, questioning its roots by emphasizing its contradictions and ambiguities.

Keywords: Engels, Bakunin, Bible, History of reading.

RESUMEN: El artículo propone un acercamiento a dos pensadores de fines del siglo XIX, Friredrich Engels y Mijail Bakunin, en tanto lectores de la Biblia. Se analizan los siguientes escritos: Dios y el Estado, de M. Bakunin (escrito hacia 1870) y «Estudio sobre la historia del cristianismo primitivo», de Engels (escrito en torno a 1890). Ambos autores son ejemplos destacados de lectores decimonónicos de la Biblia y en su acercamiento a la misma presentan algunos rasgos comunes. A su modo, críticos de la Ilustración, cada uno se apoyó en argumentos que superaran la reacción antiracionalista del Romanticismo. Bakunin y Engels vieron detrás de la razón crítica del Iluminismo una razón legitimadora de la sociedad capitalista. A la luz de esta premisa, retomaron la crítica a los «prejuicios» cristianos ya presente en los filósofos del siglo XVIII, pero radicalizándola. En tanto pensadores fuertemente anticristianos, atacaron la doctrina cristiana teórica y pasionalmente en la mayoría de sus escritos, 
intentando -explícita o implícitamente- golpearla en sus raíces explicitando sus contradicciones y ambigüedades.

Palabras clave: Engels, Bakunin, Biblia, Historia de la lectura.

Pensemos cuántas veces al leer ha cambiado el curso de la historia: Lutero y su lectura de Pablo; Marx y su lectura de Hegel; Mao y su lectura de Marx.

(Darnton, en Burke, 1998: 206)

\section{Introducción}

Con estas palabras se refiere Robert Darnton a momentos nodales de la Historia de la lectura; puntos que se destacan entre otros, pero que forman parte de un proceso que tiene como hilo conductor el esfuerzo de algunos lectores particulares por darle un sentido al mundo (Darnton, 1996). Encontrar ese sentido es el resultado de una búsqueda intensa y activa. Con respecto a las prácticas de lectura, esta búsqueda implica una apropiación de un objeto cultural específico, el texto, el discurso fijado (Cavallo y Chartier, 1998; Chartier y Hébrad, 1994). En el momento de la recepción de un texto, está presente una realidad históricosocial concreta, pero en ese telón de fondo tienen posibilidad de actuar infinitas interpretaciones, construcciones, reactualizaciones y reelaboraciones de sentido (Eco, 2010).

A partir de este marco interpretativo, en este ensayo se realiza un acercamiento a dos pensadores de fines del siglo XIX, Friedrich Engels y Mijail Bakunin, en tanto lectores de la Biblia. Como es sabido, en la tradición cristiana, la Biblia posee un carácter sagrado y los libros contenidos en ella son considerados obra de la inspiración divina; es asumida como un texto normativo para la vida que debe ser guiada por la fe. Pese a ello, como señaló Cristopher Hill, «la Biblia no es monolítica - lejos de eso. El canon aceptado ha sido construido a través de los siglos; incorpora muchas ideas y actitudes diferentes y a veces conflictivas» (Hill, 1994: 4). ${ }^{1}$

La Biblia es la piedra angular sobre la que se construyó la doctrina cristiana. Desde que el cristianismo se convirtió en religión oficial del Imperio Romano, la Iglesia ocupó un lugar preeminente en las esferas de poder y de saber. El fin

1. Traducción de la autora. 
del Antiguo Régimen trajo consigo fuertes transformaciones. Una tendencia irreversible, que comenzó a delinearse en el siglo XVII y se consolidó durante el siglo XVIII, fue la de creciente secularización; distintas voces comenzaron a expresarse en un idioma secular, más allá de sus creencias religiosas. Los pensadores iluministas rompieron explícitamente con la fe como elemento rector del mundo de las ideas y comenzaron, guiados por la razón, a dominar un universo desacralizado (Chartier, 1995:122).

A su vez, el Iluminismo del siglo XVIII manifestó una confianza ilimitada en la capacidad liberadora de la razón, pretendiendo conducir al hombre desde la oscuridad de la metafísica y la religión hasta las luces de la razón. A pesar de que la secularización y laicización del pensamiento se hizo fuertemente presente durante el siglo XIX, este hecho no provocó una indiferencia hacia las Sagradas Escrituras, sino más bien una resignificación de sus contenidos. En la segunda mitad del siglo XIX, ciertos pensadores anticristianos recurrieron a la Biblia y realizaron lecturas no ortodoxas para reafirmar las argumentaciones de sus tesis.

A continuación se analizarán los siguientes escritos: Dios y el Estado, de M. Bakunin (escrito hacia 1870) y «Estudio sobre la historia del cristianismo primitivo», de Engels (escrito en torno a 1890). ${ }^{2}$ Ambos son ejemplos destacados de lectores decimonónicos de la Biblia y en su acercamiento a la misma presentan algunos rasgos comunes. A su modo, críticos de la Ilustración, cada uno se apoyó en argumentos que superaran la reacción antiracionalista del Romanticismo (Lepenies, 1994). Bakunin y Engels vieron detrás de la razón crítica del Iluminismo una razón legitimadora de la sociedad capitalista. A la luz de esta premisa, retomaron la crítica a los «prejuicios» cristianos ya presente en los filósofos del siglo XVIII, pero radicalizándola. En tanto pensadores fuertemente anticristianos, atacaron la doctrina cristiana teórica en la mayoría de sus escritos, intentando -explícita o implícitamente-golpearla en sus raíces explicitando sus contradicciones y ambigüedades.

\section{Engels lector de la Biblia}

Se revisa aquí un artículo de Engels publicado en 1894 en Die Neue Zeit, titulado «Estudio sobre la historia del cristianismo primitivo». Este pensador y político alemán estuvo influenciado, en sus concepciones religiosas, por la lec-

2. A los fines de no basarme en una sola traducción, consulté y cotejé distintas ediciones de los textos analizados. Cuando los autores estudiados no citan explícitamente pasajes bíblicos, las referencias implícitas fueron rastreadas en la Biblia y se señala su procedencia acompañada por un asterisco. 
tura de dos obras contemporáneas: Vida de Jesús, de David Friedrich Strauss, y La esencia del cristianismo, de Ludwig Feuerbach. En su artículo, Engels no presenta un ataque directo al cristianismo. Su tesis central es que la historia del cristianismo primitivo presenta puntos de contacto con la tendencia socialista de la clase obrera. La analogía que propone es la siguiente: los dos movimientos fueron la expresión de los oprimidos y predicaron el fin de la esclavitud y la miseria; sus miembros fueron perseguidos y sus partidarios proscriptos; ambos surgieron y se desarrollaron bajo regímenes indiscutiblemente opresivos -Roma y los estados burgueses-. Sin embargo, la diferencia central radicaría en el hecho de que el primer cristianismo no pretendía alcanzar una transformación social en este mundo, sino que se preocupaba por el más allá y la vida eterna. En contrapartida, el socialismo tendría como meta transformar la sociedad y redimirse en este mundo.

Al realizar un análisis del cristianismo primitivo, basado primordialmente en el libro del Apocalipsis, Engels demuestra un conocimiento de los estudios bíblicos realizados hasta el momento; sostiene que la crítica bíblica alemana proporcionó la base científica del conocimiento de la historia del cristianismo. Presenta dos tendencias dentro de esta crítica, una de las cuales es la de la Escuela Teológica de Tubinga, cuyo exponente destacado es David Friedrich Strauss, quien realizó un examen crítico de los cuatro evangelios del Nuevo Testamento, arribando a la conclusión de que los relatos no pertenecían a testigos oculares, y, por lo tanto, debían ser considerados apócrifos o no históricos. La segunda tendencia está representada solo por Bruno Bauer, quien rastreó en el cristianismo los elementos judíos, pero también los grecoalejandrinos, grecorromanos y griegos. Así, este autor rompió con la mirada que sostenía que el cristianismo había derivado del judaísmo y que en un segundo momento había sido exportado e impuesto desde Judea al resto del mundo grecorromano. Luego de presentar ambas miradas, Engels afirma que en el Nuevo Testamento existe solo un libro del que puede determinarse la fecha de redacción, el Apocalipsis de San Juan, redactado en torno al año 68; por lo tanto, afirma que es el testimonio más cercano a la vida de Jesús y es el que presenta más fielmente los primeros tiempos del cristianismo. Por la cercanía temporal a lo ocurrido, el libro es presentado como legítimo mucho más que los cuatro evangelios, construidos posteriormente. Partiendo de esta premisa, destaca: «y como este libro [...], que es en apariencia el más obscuro de la Biblia, ha pasado a ser hoy, merced a la crítica alemana, el más comprensible y el más transparente de todos, se me permitirá hablar de él a mis lectores» (Engels, 1946: 20). Esta cita es contundente para pensar a Engels en tanto lector activo, ya que no solo se apropia del significado que los críticos alemanes propusieron para uno de los libros del Nuevo Testamento sino que lo reformula para sostener su propia tesis. 
Engels presenta principios que legitiman el uso del Apocalipsis de San Juan; especula sosteniendo que si el autor es quien dice ser, sería una excepción en la literatura apocalíptica. Afirma que el autor era un hombre reconocido entre los cristianos del Asia Menor, y que este hecho está confirmado por el tono de las epístolas a las siete comunidades (*Apocalipsis, I, 4; II; III). En este punto, comienza el acercamiento directo al libro del Apocalipsis. El autor describe, sin hacer mención explícita, lo relatado en él (basa su descripción en el * , 4 a 14). Detiene allí su análisis para señalar que, desde el principio del libro, se presenta un cristianismo distinto al que fue adoptado como religión universal por Constantino; para afirmarlo se basa en la existencia de los «siete espíritus» (*I, 4; III, 1); esta choca con el principio de la Trinidad donde existe un Espíritu Santo único.

Engels continúa su análisis centrándose en la figura de Cristo. Lo presenta señalando su resurrección, su sacrificio como cordero para salvar los pecados del mundo. Se basa en el capítulo I, 5 a 8 , y sostiene que allí está la clave para que el cristianismo se convierta en religión universal, ya que el cordero sacrificado por los pecados del mundo, con su sangre, logró redimir a todo linaje, pueblo, lengua y nación $(* \mathrm{v}, 9)$. Al fijar el «sacrificio simbólico» en la eucaristía, desaparecía la necesidad de todo sacrificio ulterior, y por consiguiente, se eliminaba la base de numerosas ceremonias paganas. Así, el cristianismo, presentando un gran sacrificio voluntario, la muerte del mismísimo hijo de Dios, instaló el fin de los sacrificios cuasi rutinarios de las religiones semitas y europeas preexistentes.

En el libro completo del Apocalipsis, según señala Engels, todos los actores son considerados judíos, hijos de Israel (*por ejemplo, VII) y no cristianos; esto evidenciaría la falta de autoreconocimiento de los cristianos como tales: «el cristianismo inconsciente de entonces estaba muy lejos de ser la religión universal adoptada dogmáticamente por el Concilio de Nicea» (Engels, 1946: 27). Sin embargo, el autor destaca que hay algo que permite valorar a estos primeros cristianos carentes de identidad y, a su vez, reivindicar el socialismo: propone pensar a ambos como movimientos de masas conformados por los oprimidos, un elemento social potencialmente revolucionario. De todas formas, Engels destaca que las condiciones en las que se desarrolló el cristianismo impedían una acción vital que condujera a estos elementos a la liberación inmediata, su esperanza estaba depositada en un futuro paraíso celeste (*I, 1 y 3 ; III, 11; XXII, 12 y 20$)$.

Retomando la validez del Apocalipsis, Engels destaca que las visiones apocalípticas han sido copiadas en gran parte del Antiguo Testamento, sobre todo del libro de Ezequiel. Resume el Apocalipsis, casi parafraseándolo, desde el capítulo v hasta el XXII, e intercala sus comentarios. En esta síntesis resalta una serie de imágenes de crueldad, sacrificio, plagas y castigos varios, repetidos en múltiples ocasiones (*VII; IX; XV, entre otros). Encuentra allí el germen de la 
religión que en el siglo IV se universalizaría y se convertiría en institución represiva: «no se trata aquí, pues, de la "religión del amor", del "amad a los que os odian", "bendecid a aquellos que os maldigan", etc.; predícase aquí abiertamente la venganza, el odio, la honrada venganza contra los enemigos del cristianismo» (Engels, 1946: 40).

Para finalizar su análisis bíblico, Engels señala que en el Apocalipsis no existen rasgos del pecado original, ni del bautismo, ni de la eucaristía como tal; afirma que todas ellas son construcciones posteriores de una Iglesia en el poder, que nada tienen que ver con el movimiento del cristianismo primitivo: «la fe de dichas primeras comunidades de temperamento belicoso, jovial, difiere totalmente de la Iglesia triunfante posterior» (Engels, 1946: 51 y 52).

Luego de presentar un exhaustivo análisis del libro del Apocalipsis y de demostrar un conocimiento tanto de la Biblia en su totalidad como de los estudios críticos bíblicos existentes, el autor finaliza su exposición. Puede pensarse este artículo de Engels como una alerta a sus lectores; el desarrollo histórico del cristianismo presenta una «degeneración» en relación a su estado primitivo, caracterizado como un movimiento de masas y revolucionario. Este hecho, desde su perspectiva, debía ser tenido en cuenta por el movimiento obrero moderno para no degenerarse ni corromperse; parecería estar incitando a la movilización, señalando indirectamente que la pasividad, encarnada en los primeros cristianos en la esperanza de salvación ultraterrena, conllevaría una indefectible pérdida de unidad y de fuerza performativa. Engels parecería estar privilegiando la movilización efectiva de las masas en búsqueda activa de la felicidad terrena. En este sentido, el escrito tiene una finalidad moralizante: destaca un «deber ser» del socialismo como movimiento de acción transformadora.

\section{Mijail Bakunin lector de la Biblia}

Bakunin, quien se destacó por ser un teórico del anarquismo en el marco de sus escritos, consideraba la existencia de todo tipo de autoridad como negación de la libertad humana (Carr, 1985). La frase que resume este principio es «si Dios existe, el hombre es esclavo». La divinidad es la negación de la humanidad: cuanto más grande es la primera, más miserable es la segunda. Este principio tiene su correlato terrestre en el Estado, ya sea este monarquía o república, o esté basado en el autoritarismo o la democracia. Todas las formas estatales violan las leyes de igualdad, considerada por este pensador como la suprema condición de la libertad y la humanidad.

La verdadera libertad del hombre debe consistir en la «voluntaria obediencia» a leyes sociales reconocidas como tales por los hombres y no establecidas por una autoridad exógena, ya sea esta humana o divina. Según Bakunin, la 
solidaridad de una comunidad es la esencia del género humano. Estos principios definen, apenas en parte, a esta personalidad ácrata.

Como es sabido, no es una tarea sencilla atribuir una única matriz teórica a la doctrina anarquista, ya que pueden encontrarse influencias del racionalismo del siglo XVIII, el idealismo absoluto y el positivismo evolucionista; sin embargo, es indiscutible una radical oposición al sistema socio-económico capitalista y a su correlato político, el Estado burgués. La propuesta de Bakunin es la de una revolución social contra las estructuras socio-económicas, como un acto espontáneo que hará que los hombres reasuman su humanidad, dando paso a un nuevo régimen contractual donde se desarrollará una solidaridad fraterna e igualitaria, respetuosa de las singularidades. Desde su perspectiva, el federalismo libertario superaría las fronteras políticas y nacionales.

El texto aquí comentado es Dios y el Estado (escrito hacia 1870). Se trata de una compilación de manuscritos encontrados y editados conjuntamente por poseer una afinidad temática. En él se encuentra una oposición radical a la autoridad; el autor se opone a cualquier tipo de Estado, considerándolo como sucedáneo del «tirano celeste». El prólogo de una de las ediciones consultadas está a cargo de C. Ferrer, quien ofrece una clave de lectura al sostener que no debe identificarse a Bakunin con un materialismo ateo y cientifista: «el combate contra la superchería ontológica no es iniciado con la intención de comprobar la inexistencia del Todopoderoso, como si de un gélido dato científico se tratase, pues Bakunin afirma que Dios existe en tanto idea y dotada de potencia simbólica justifica la entronización de tiranos terrestres» (Bakunin, 1990: 13).

Así, el misterio de la existencia divina permite la persistencia del ideal jerárquico. Dios es el vértice de la pirámide, es la autoridad en estado supremo que viabiliza la existencia de intermediarios terrestres. Nos encontramos ante un antiteísmo visceral, antes que un ateísmo científico; una oposición franca y enérgica frente a un Dios considerado terrible y vengativo que impide el desenvolvimiento de la Humanidad.

A diferencia de Engels, Bakunin no hace referencia a ningún estudio bíblico. Utiliza unas pocas imágenes de la Biblia, pero no especifica su procedencia, y, basándose en ellas, a la vez las abandona para entregarse a una prosa más pasional que teórica. En el primer apartado, titulado «El principio de autoridad», señala la existencia de condiciones esenciales del desenvolvimiento humano, tanto individual como colectivo, y resume estas condiciones en tres elementos: la animalidad humana, el pensamiento, la rebeldía. Sostiene que estas características inherentes a la condición humana se hacen evidentes desde el momento del surgimiento de la especie. Yuxtaponiendo el evolucionismo darwiniano con el acto divino de la creación, el autor sostiene que los primeros antepasados de los hombres, nuestros Adanes y nuestras Evas, fueron «primos» próximos de los gorilas, dotados en un grado superior respecto de los animales de las otras 
especies de dos facultades, la de pensar y la de rebelarse. Para ampliar esta afirmación, el autor recurre a la Biblia, que describe como «un libro muy interesante y a veces muy profundo cuando se lo considera como una de las más antiguas manifestaciones de la sabiduría y de la fantasía humanas que han llegado hasta nosotros, expresa esta verdad de una manera muy ingenua en su mito del pecado original» (Bakunin, 1990: 18).

Sin citar explícitamente sus contenidos, Bakunin presenta irónicamente el acto de la creación contenido en el libro del Génesis; sostiene que Jehová creó a Adán y Eva por capricho, para mitigar su hastío y procurarse esclavos, y que puso a su disposición toda la tierra para que de ella gozaran, prohibiendo expresamente que tocaran los frutos del árbol de la ciencia (*Génesis II, 17). Interpreta este hecho como un deliberado deseo de Dios de que el hombre permaneciera en su estado animal, anulando su razón, es decir, el instrumento principal de emancipación; destaca: «llega Satanás, el eterno rebelde, el primer libre pensador, el emancipador de los mundos. Avergüenza al hombre de su ignorancia y de su obediencia animal; lo emancipa [...], impulsándolo a desobedecer y a comer el fruto de la ciencia» (Bakunin, 1990: 19).

Posteriormente, Bakunin recuerda las maldiciones a Satanás, al hombre y a toda su descendencia (*Génesis III, 14 a 23); sostiene que los teólogos intentan justificar esta evidencia de un Dios colérico y vengativo, resaltando el misterio de la Redención, es decir, enfatizando el hecho de que Dios envió a su hijo para que fuese muerto por los hombres. Afirma que este misterio es un absurdo, ya que Dios no salvó a todo el mundo, sino que prometió un paraíso donde habría unos pocos elegidos (*por ejemplo, Lucas XIII, 23 y 24). Así, la llamada igualdad cristiana culmina en ser un evidente privilegio para un reducido número de elegidos por la gracia divina.

Retomando el tema del pecado original, luego de presentar los hechos narrados con especial ironía, se encuentra una de las escasas citas bíblicas, pero sin referencia; Bakunin presenta lo que Dios se dijo a sí mismo, a saber: «he aquí que el hombre se ha convertido en uno de nosotros, sabe del bien y del mal; impidámosle, pues, comer del fruto de la vida eterna, a fin de que no sea inmortal como nosotros» (*Génesis III, 22). El autor intenta pensar el sentido último del pecado original y lo considera un mito: el hombre se ha emancipado, separándose de su animalidad, y ha comenzado su historia. Bakunin atribuye esta posibilidad a un acto de desobediencia y de avidez de conocimiento, asociando de manera estrecha la rebeldía con el pensamiento. Reivindica, de este modo, a Satanás y a Eva por haber inducido y realizado este acto. Esta vindicación concluye en una propuesta: la ciencia debe guiar la emancipación del hombre.

Si bien en los constantes ataques de Bakunin al idealismo, la metafísica y la teología se encuentran referencias al pecado original, interesa aquí subrayar un pasaje en el que el autor apela al sentido común del lector para parodiar la 
narración bíblica del Génesis en relación a la tentación; sostiene: «el más simple padre de familia sabe muy bien que basta que se impida a los niños tocar una cosa para que un instinto de curiosidad los fuerce absolutamente a tocarla. Por tanto, si ama a los hijos y si es realmente justo y bueno, les ahorrará esa prueba tan inútil como cruel» (Bakunin, 1990: 164). De este modo, evidencia la deliberada maldad de la prohibición de comer los frutos de la sabiduría. Ante una posible objeción de un defensor del mensaje bíblico que sostuviera que Dios conocía de antemano que se concretaría la tentación, pero que sabía también que ese momento era una condición necesaria para la futura redención del hombre, el autor sostiene que, incluso así, ese «Dios de bondad» no debería haber reaccionado en forma tan extrema: «no se contenta con maldecir a los desgraciados desobedientes, maldice a toda su descendencia [...], no se contenta con maldecir a los hombres, maldijo [...] su propia creación, que había encontrado tan bien hecha» (Bakunin, 1990: 165).

Como se mencionó ya, en los escritos de Bakunin nos encontramos no solo con sugerencias, como en el caso de Engels, de la caracterización bíblica de Dios como vengativo y cruel, de donde podrían surgir los fundamentos de una religión autoritaria y opresiva; Bakunin se ocupa, además, de acentuar constantemente este punto en particular; por ejemplo, destaca: «Jehová, de todos los buenos dioses que han sido adorados por los hombres, es ciertamente el más vanidoso, el más feroz, el más injusto, el más sanguinario, el más déspota y el más enemigo de la dignidad y de la libertad humana» (Bakunin, 1990: 18). Por su parte, al igual que en Engels, se encuentran en su prosa referencias al pasaje del politeísmo al monoteísmo. Bakunin sostiene que la religión es una ilusión colectiva muy poderosa y que su origen se remonta a una lejana antigüedad; es esta larga trayectoria histórica la que habría posibilitado su conversión en alma y pensamiento colectivo, trayectoria que no estuvo privada de mutaciones. El pensador ruso afirma que del «materialismo religioso» del paganismo, cuyos dioses no eran negación de las cosas reales sino una exageración fantástica de las mismas, se produjo una transición a la fe espiritualista de los cristianos legitimada por la teología, que se basa en el principio «credo quia absurdum». Remata estas aseveraciones con la siguiente afirmación sobre la forma en la que cristalizó la idea del dios de los cristianos: «primero fetiches groseros se hicieron poco a poco espíritus puros, con existencia fuera del mundo visible, y en fin, a continuación de un largo desenvolvimiento histórico, acabaron por confundirse en un solo ser divino, espíritu puro, eterno, absoluto, creador y amo de los mundos» (Bakunin, 1990: 80).

Bakunin sostiene que Moisés y los profetas predicaron un dios único y nacional; el dios de los judíos no renegaba de la existencia de otros dioses, pero pretendía que su pueblo solo lo adorase a él. «Jehová era un dios muy envidioso y su primer mandamiento fue este: "Soy tu dios y no adorarás a otros dioses más 
que a mí"» (Bakunin, 1990: 82) (*Éxodo, xx, 3). Pero el ser supremo no podía ser un dios nacional, debía ser el dios del mundo entero, debía convertirse en divinidad en detrimento de la Humanidad. Considera este acto como la evidencia del más absoluto egoísmo e individualismo, que encontró su expresión más acabada en el monoteísmo, donde, desde su perspectiva, están contenidos todos los gérmenes de la moral individualista.

A los fines de demostrar este exacerbado individualismo, el autor recurre a los mandamientos contenidos en el decálogo (*Éxodo, Xx), sosteniendo que estos se dirigen casi exclusivamente al individuo. Ironizando extremadamente el contenido del decálogo para demostrarlo, el autor nos dice: «no matarás (exceptuados los casos muy frecuentes en que te lo ordene yo mismo...); no robarás ni la propiedad ni la mujer ajenas...; respetarás a tus padres. Pero sobre todo me adorarás a mí, el dios envidioso, egoísta, vanidoso y terrible, y si no quieres incurrir en mi cólera, me cantarás alabanzas y te prosternarás eternamente ante mí» (Bakunin, 1990: 151).

En suma, Bakunin sostiene que la religión fue una funesta imposición al pueblo y el instrumento preciso para la salvación de la burguesía, que había entendido que no podía existir el Estado sin religión y sin Dios. En este punto de sus argumentos, sostiene que la Iglesia y el Estado esclavizan por definición al hombre. De este modo, pretende evidenciar la inconsistencia de la clase dominante presentando a los principios cristianos como incompatibles en esencia con los valores burgueses -opone la salvación de las almas a la acumulación de bienes materiales-. Una vez más, recurre a la Biblia y destaca: «Jesucristo ha dicho a sus discípulos: "No amontonaréis tesoros en esta tierra, porque donde están vuestros tesoros está vuestro corazón"; y otra vez: "es más fácil que una maroma [un camello, según otra versión] pase por el agujero de una aguja, que un rico entre en el reino de los cielos"» (Bakunin, 1990: 108) (*Lucas, XII, 33 y 34; Mateo, XIX, 23 y 24; Marcos X, 25; respectivamente). Expuestos estos planteos, su propuesta intenta interpelar al hombre a que se rebele contra todo tipo de tiranía para realizar su libertad individual y alcanzar la libertad.

Los escritos de Bakunin forman parte de un programa concreto, y es coherente ver cómo el autor, que propone una revolución social para salir del pantano de injusticias en el que se halla sumida la Humanidad (Guérin, 1985), reivindica y levanta la bandera de la libertad en contra de cualquier principio de autoridad, hecho que guía su lectura poco ortodoxa de las Sagradas Escrituras.

\section{Palabras finales}

Durante siglos, las Santas Escrituras se presentaron ante el pueblo cristiano como un texto hermético al que se podía tener acceso solo por medio de un 
intermediario de la Iglesia. Si bien la Reforma religiosa inspirada por Lutero en el siglo XVI y su principio de "solo Escritura» marcó un corte en la imposición de la mediación eclesiástica entre los creyentes y la Biblia, este hecho afectó solamente a algunas zonas de Europa, aquellas en las que se desplegaron las vertientes desprendidas del protestantismo (Chartier, 1995b). De este modo, en vastas regiones, la Iglesia marcó una dirección en relación a la lectura de las Escrituras. La Biblia devino soporte de un sentido transmitido durante siglos y se enseñó una forma precisa para que fuera leída correctamente. Se consolidó así el perfil del lector-creyente, cuyos márgenes de actividad en el acto de lectura se vieron limitados al asumir la Biblia como un texto normativo. Las lecturas de Engels y Bakunin pueden pensarse como espejos invertidos de esta figura de lector; ambos pretendieron dejar de pensar la Biblia como un texto cerrado o monumento histórico-literario para, en cambio, abrirlo a sus interpretaciones y provocadoras preguntas. Es así que se propusieron desarmar y cambiar de signo contenidos presentados como cerrados e impenetrables.

$\mathrm{Al}$ analizar la obra de Bakunin es fácil entender que recurre a la Biblia con fines concretos. Si bien utiliza unas pocas imágenes de las Santas Escrituras, parte de las mismas para entregarse a extensos párrafos críticos más pasionales que teóricos. Su acercamiento a la Biblia está motivado por la intención sistemática de subrayar contradicciones. De este modo, el intelectual ruso recurre a la piedra de toque de la doctrina cristiana y la lee solo para evidenciar sus inconsistencias y cambiar radicalmente de signo el sentido dado a sus contenidos dentro de la tradición cristiana. En su lectura de la Biblia se filtran influencias del positivismo y del evolucionismo que se yuxtaponen con su oposición a cualquier tipo de autoridad (Pagels, 1990). De este modo, el autor recurre al texto bíblico para criticar los principios de autoridad y reivindicar la faceta emancipadora de la ciencia. Así, considera que atacando agresivamente los pilares sobre los que se basa el cristianismo puede desacreditar, por extensión y realizando una analogía un tanto osada, los cimientos de los estados de carácter burgués.

Engels, por su parte, se inclina por una lectura más teórica de la Biblia y presenta una mirada menos pasional. De hecho, se basa en las obras de David Friedrich Strauss y Ludwig Feuerbach para realizar sus críticas. Es decir, lee la Biblia en sintonía con aquellos que la han estudiado. Si bien su postura crítica frente a la religión cristiana ya estaba presente en La Sagrada Familia (1845), texto en el que entre una crítica al idealismo de los jóvenes hegelianos y al materialismo mecanicista se deslizan comentarios antirreligiosos tan sutiles como contundentes, fue en «Estudio sobre la historia del cristianismo primitivo» donde su preocupación por los contenidos literales de la Biblia y sus implicaciones quedó de manifiesto. Desde un primer momento, se sirve de las obras mencionadas para caracterizar al Apocalipsis como un tipo de texto basado en la superchería y la charlatanería. De este modo, a la vez que descalifica el «género 
apocalíptico», se sirve del análisis del mismo para mostrar las inconsistencias del cristianismo como doctrina. Su lectura no hace más que reafirmar con fundamentos teóricos y especulativos la famosa frase aparecida en la Contribución a la crítica de la Filosofía del Derecho de Hegel (Marx, 1843): «la religión es el opio de los pueblos». En suma, se ha tratado de mostrar cómo ambos pensadores, en tanto lectores críticos, asumieron la necesidad de criticar de manera sistemática la Biblia, de destruir ese monumento sagrado desde sus cimientos para, posteriormente, presentar lecturas superadoras y revolucionarias en contra de lo que consideraban una plataforma de ideas que habilitaba a distintas formar de sumisión de la Humanidad.

\section{Referencias bibliográficas}

Bakunin, M. (1990): Dios y el Estado, Buenos Aires, Altamira.

CARR, E. (1970): Bakunin, México-Barcelona, Grijalbo.

Cavallo, G. y R. Chartier (1998): Historia de la lectura en el mundo occidental, Madrid, Taurus.

Chartier, R. (1995 a): Espacio público, crítica y desacralización en el siglo XVIII. Los orígenes culturales de la Revolución Francesa, Barcelona, Gedisa.

- (1995 b): Sociedad y escritura en la Edad Moderna, México, Instituto Mora, $1995 \mathrm{~b}$.

Chartier, A-M. y J. HÉbraRd (1994): Discursos sobre la lectura (1880-1980), Barcelona, Gedisa.

Darnton, R. (1996): «Historia de la lectura» en Burke, P. (1996): Formas de hacer la Historia, Madrid, Alianza. 177-208.

Eco, U. (2010): Lector in fabula. La cooperazione interpretativa nei testi narrativi, Milano, Bompiani.

Engels, F. (1946): «Estudio sobre la historia del cristianismo primitivo», en Engels, F., La filosofía y la vida, Buenos Aires, Tor.

Engels, F. (1959): «Sobre la historia del cristianismo primitivo» en MARX, K.; F. Engels, Sobre la religión, Buenos Aires, Cartago.

GuÉRIN, D. (1985): El anarquismo. De la doctrina a la acción, Buenos Aires, Editorial Altamira.

Hill, Сн. (1994): The English Bible and the Seventeenth-Century Revolution, London, Penguin Books.

LEPENIES, W. (1994): Las tres culturas. La sociología entre la literatura y la ciencia, México, Fondo de Cultura Económica.

Pagels, E. (1990): Adán, Eva y la serpiente, Barcelona, Crítica. 